\title{
Climate sensitivity of a millennium-long pine chronology from Albania
}

\author{
Andrea Seim ${ }^{1,2, *}$, Ulf Büntgen ${ }^{1,3}$, Patrick Fonti ${ }^{1}$, Hajri Haska ${ }^{4,8}$, Franz Herzig $^{5}$, \\ Willy Tegel $^{6}$, Valerie Trouet ${ }^{7}$, Kerstin Treydte ${ }^{1}$ \\ ${ }^{1}$ Swiss Federal Research Institute, WSL, Zürcherstrasse 111, 8903 Birmensdorf, Switzerland \\ ${ }^{2}$ Regional Climate Group, Department of Earth Sciences, University of Gothenburg, 40530 Gothenburg, Sweden \\ ${ }^{3}$ Oeschger Centre for Climate Change Research, Zähringerstrasse 25, 3012 Bern, Switzerland \\ ${ }^{4}$ Ministry of Environment, Forestry and Water Administration, Rruga e Durresit 27, Tirana, Albania \\ ${ }^{5}$ Bavarian State Department for the Protection of Monuments and Sites, 86672 Thierhaupten, Germany \\ ${ }^{6}$ Institute for Forest Growth, University of Freiburg, 79085 Freiburg, Germany \\ ${ }^{7}$ Laboratory of Tree-Ring Research, University of Arizona, Tucson, Arizona 85721, USA \\ ${ }^{8}$ Present address: Agricultural University of Tirana, Faculty of Forestry Science, 1029 Kamez-Tirana, Albania
}

\begin{abstract}
Considerable progress has been made in assessing European climate variations of the last millennium, but little is known about the Mediterranean region and particularly its eastern part including the Balkan Peninsula. This area, however, will be particularly vulnerable to a predicted temperature increase and precipitation decrease, likely resulting in amplified drought extremes and episodes. Here we present a well-replicated composite tree-ring width chronology of millennial length from Albania, Balkan Peninsula. The Pinus heldreichii Christ dataset contains 302 series from 217 living and dead trees from 3 high-elevation sites, and spans the years 968-2008. Signal strength and growth-climate relationships were investigated using subsets according to location, age class, and growth level, as well as differently detrended chronology versions. Growth comparisons amongst the 3 sites' chronologies, between age classes and between growth-rate groups reveal an overall strong common signal. Growth-climate relationships over the last $100 \mathrm{yr}$, however, indicate that tree-ring formation does not depend on one single dominant factor, but rather on various combinations of summer precipitation and temperature resulting in temporally varying drought sensitivity. Our results emphasize a mixed and variable climate signal, corresponding with findings from other $P$. heldreichii sites across the Balkan Peninsula and Southern Italy.
\end{abstract}

KEY WORDS: Tree-ring width $\cdot$ Pinus heldreichii $\cdot$ Dendroclimatology $\cdot$ Albania $\cdot$ Mediterranean climate $\cdot$ Climate reconstruction

\section{INTRODUCTION}

Recent global warming and its potential impact on the hydrological cycle and subsequent ecological implications strengthen the need to quantify the degree of past natural climate variability (IPCC 2007). This demand becomes even more critical for drought-sensitive and highly populated regions with intense agricultural background (Büntgen et al. 2011). The Mediterranean region will be par- ticularly vulnerable to a predicted temperature increase and precipitation decrease, likely resulting in amplified drought extremes and episodes (e.g. Gao \& Giorgi 2008). Assessment of regional-scale climate variability, however, is complicated (see Luterbacher et al. 2006 for a review) due to complex interactions of synoptic circulation patterns (Dünkeloh \& Jacobeit 2003, Xoplaki et al. 2003, 2004, Nicault et al. 2008), and specific local thermal and orographic situations. 
A dense temporal and spatial coverage of paleoclimatic indicators is therefore required to reconstruct inter-annual to multi-centennial climate variability. In this context, tree rings are considered the most important high-resolution climate proxy archive for large areas around the Mediterranean, besides historical documentary data (Luterbacher et al. 2006). Dendroclimatological efforts in assessing past climate variations of high mountain environments have been made in the western Mediterranean, with emphasis on the northern Iberian Peninsula (e.g. Gutiérrez 1989, Macias et al. 2006, Büntgen et al. 2008, 2010), and northern Africa (Guiot et al. 1979, Esper et al. 2007), for instance. Investigations in the central part of the Mediterranean basin are rather sparse (Serre-Bachet 1985, Todaro et al. 2007), and the eastern part of the Mediterranean basin is dominated by work concentrated in Turkey, where tree growth has generally been described as sensitive to hydroclimatic extremes (e.g. D'Arrigo \& Cullen 2001, Touchan et al. 2005, Akkemik et al. 2008).

Specifically on the Balkan Peninsula, a key region in the climatic transition zone between the western and eastern Mediterranean and also between the Mediterranean and central European synoptic regimes (e.g. Xoplaki et al. 2003, 2004), reliable proxies are scarce (Vakarelov et al. 2001, Popa \& Kern 2009). Preliminary studies have been conducted in Bulgaria (Panayotov et al. 2009, 2010, Trouet et al. 2012) and Greece (Brandes 2007, Griggs et al. 2007), testing growth-climate relations of high-elevation pines. By using maximum latewood density rather than treering width (TRW), Seim et al. (2010) showed the potential for temperature reconstructions based on Pinus heldreichii, an endemic, long-living highelevation species on the Balkan, as well as in southern Italy (Barbero et al. 1998). Old stands of this species are abundant in Albania, but little tree-ring research has been carried out there so far. First attempts, however, demonstrated the potential to develop composite chronologies from living trees and historical timber (Westphal et al. 2010), which likely even reflect a pronounced drought signal when carefully collected low-elevation pine trees Pinus nigra Arnold were considered (Levanič \& Toromani 2010).

Here we present a dataset of 302 samples from 217 high-elevation pines across Albania spanning the 617-2008 period. Temperature, precipitation, and drought sensitivity of the new data were analyzed with particular emphasis on temporal stability and potential age-related changes in response to climate. Finally, we discuss our results in the light of potential long-term climate reconstructions for Albania.

\section{MATERIALS AND METHODS}

\subsection{Tree-ring data}

Tree-ring sampling was performed in order to develop well-replicated, long, and climate-sensitive chronologies including different age classes. From 131 living trees, 47 disk and 255 core samples were collected, and 86 samples were derived from stumps of recently logged trees or from dry dead wood remains. We sampled at 3 high-elevation sites along a north-south transect in Albania: Thethi (AT), Fushe Lura (AL) and the Cuka Partisan (AP) (Fig. 1). All sites were located in open forest stands near the upper local treeline on shallow soils. The most northern site, AT $\left(42^{\circ} 25^{\prime} \mathrm{N}, 19^{\circ} 46^{\prime} \mathrm{E}\right)$, is located in the Albanian Alps, and 41 trees were sampled between 1700 and $1900 \mathrm{~m}$ above sea level (a.s.l.) on a southeast-exposed slope. The AL site $\left(41^{\circ} 48^{\prime} \mathrm{N}, 20^{\circ} 14^{\prime} \mathrm{E}\right)$ is located in the Lura mountain range in central Albania, where 89 trees were sampled between 1800 and $2000 \mathrm{~m}$ a.s.l. on a steep southwest-exposed slope. We complemented cores of living trees with samples from $10 \operatorname{logs}$ (>500 yr) found in local sawmills close to

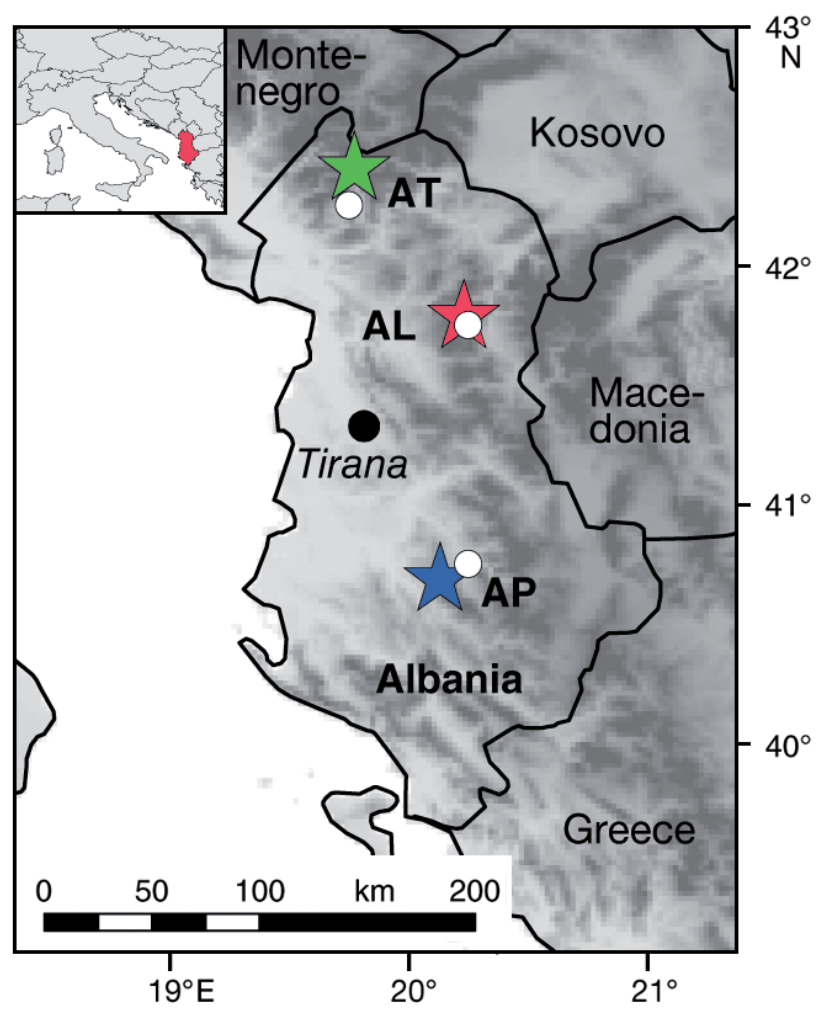

Fig. 1. Tree sampling sites: Thethi (AT, green), Fushe Lura $(\mathrm{AL}, \mathrm{red})$, and Cuka Partisan (AP, blue). White circles: grid points used for climate calibration (CRUTS3) 
this site. The AP site in the Tomorri massif $\left(40^{\circ} 42^{\prime} \mathrm{N}\right.$, $20^{\circ} 8^{\prime} \mathrm{E}$ ) is the southernmost location, where 77 trees were sampled between 1900 and $2100 \mathrm{~m}$ a.s.l.

\subsection{Chronology development}

Annual TRW variations were measured with a semi-automated measurement system with $0.01 \mathrm{~mm}$ precision (LINTAB ${ }^{\mathrm{TM}}-5$ and PAST 4). First, TRW patterns were visually cross-dated and their dating quality was verified using COFECHA software (Holmes 1983). The 'pith-offset' (PO), i.e. the number of missing years between the innermost ring on a core sample and the pith, was estimated to obtain the absolute biological age of each tree. The PO estimates were based on the growth rates and the curvatures of the tree rings from the existing material and if possible, compared with the second core of the same tree (Bräker 1981).

The whole dataset was analyzed in 4 different ways: (1) by site ( 3 groups: AT, AL, AP), (2) by age class: (3 groups: <250 yr, 250 to $400 \mathrm{yr},>400 \mathrm{yr}$ ), (3) by growth performance (2 groups: slow- and fastgrowing trees), and (4) the Albanian (ALB) composite chronology, containing all data. The range of age classes and growth-performance groups was defined in order to obtain a balanced distribution of records per group. Age-class splitting was performed based on the length of each series. Nearly equal replication was reached by generating a young age class up to $250 \mathrm{yr}$ including 80 series, a middle age class from 250 to 400 yr including 115 series, and an old age class $>400$ yr including 107 series. The average growth rate (AGR) of $0.88 \mathrm{~mm} \mathrm{yr}^{-1}$ after truncation of the first $100 \mathrm{yr}$ of each series was used as the threshold to distinguish slow- and fast-growing subsets, while the AGR of trees younger than $100 \mathrm{yr}$ was individually checked for this classification. This method reduced possible bias caused by increased growth rates during the juvenile phase of the trees. The fast-growing group consisted of 114 series and the slow-growing group of 158 series.

To remove age-related trends while preserving climatic information on inter-annual to longer-term time-scales from each individual raw and powertransformed (PT) TRW series (Cook \& Peters 1997), an array of 5 commonly used detrending functions was applied: (1) the regional curve standardization (RCS; Becker et al. 1995) with and (2) without PO estimates, (3) the negative exponential function, and (4) individual cubic smoothing spline (SPL) with $150 \mathrm{yr}$ and
(5) $300 \mathrm{yr}$ frequency-response cut-off at $50 \%$. TRW chronologies of the 3 sites, the combined ALB composite, and of the age class and growth-rate subsets were developed as weighted means of the detrended series after variance stabilization (Frank et al. 2007). The strength of the common variance between the single series was assessed using the inter-series correlation (Rbar) and the expressed population signal (EPS; Wigley et al. 1984) calculated over 50 yr periods with 25 yr of overlap for each chronology.

\subsection{Signal detection}

Due to the scarcity and brevity of local instrumental data (e.g. Seim et al. 2010), growth-climate relations (calculated as Pearson's correlation coefficients) between the various TRW chronologies and different climate parameters were performed using highresolution gridded $\left(0.5^{\circ} \times 0.5^{\circ}\right)$ monthly resolved climate indices including temperature, precipitation, and the self-calibrated Palmer Drought Severity Index (scPDSI) (CRUTS3; Mitchell \& Jones 2005, van der Schrier et al. 2006). The closest grid points to the 3 sampling sites were $40^{\circ} 45^{\prime} \mathrm{N}, 20^{\circ} 15^{\prime} \mathrm{E}_{\text {; }} 42^{\circ} 15^{\prime} \mathrm{N}$, $19^{\circ} 45^{\prime} \mathrm{E}$; and $41^{\circ} 45^{\prime} \mathrm{N}, 20^{\circ} 15^{\prime} \mathrm{E}$ for $\mathrm{AT}, \mathrm{AL}$ and $\mathrm{AP}$, respectively (Fig. 1). Cross-correlation for annual temperature, precipitation, and scPDSI was significantly positive amongst the 3 grid points $(0.98,0.85$ and 0.82 , respectively; $\mathrm{p}<0.01$ ). The mean of the 3 grid points was used for comparison with the ALB chronology. Correlations were computed over an 18 mo window from the previous year's May to the current year's October for the period of overlap (1901 to 2002). Seasonal temperature means and precipitation sums for the 3 sites are highlighted using winter (DJF; previous December to current February) and summer (JJA; June to August) seasons (Table 1).

\section{RESULTS}

\subsection{Data characteristics and growth trends}

The number of cross-dated series per site is 54 for AT and 124 each for AL and AP. The mean segment length (MSL) of the 3 sites ranges from $275 \mathrm{yr}$ at AT to $397 \mathrm{yr}$ at AL (Fig. 2). By adding recently logged trees and dry dead wood to these datasets, we were able to cover the periods 1417-2007 at AT, 968-2008 at AL, and 1443-2008 at AP, with a minimum replication of 5 series. The longest series was derived from a sawmill log in the AL region, which counts 1017 tree rings, and 
Table 1. Climate conditions obtained from the CRUTS3 data at 3 Albanian sites (AT: Thethi, AL: Fushe Lura, AP: Cuka Partisan) classified in winter (DJF: previous Deccurrent Feb), in summer (JJA: Jun-Aug), and for annual (yr) temperature means and precipitation sums for 1961-1990

\begin{tabular}{|lrrrrrr|}
\hline \multirow{2}{*}{ Site } & \multicolumn{3}{c}{ Temperature $\left({ }^{\circ} \mathrm{C}\right)$} & \multicolumn{3}{c|}{ Precipitation $(\mathrm{mm})$} \\
& DJF & JJA & Yr & DJF & JJA & Yr \\
\hline \multirow{2}{*}{ AT } & -2.3 & 15.4 & 6.6 & 305.7 & 230.1 & 1148.3 \\
AL & 0.5 & 18.2 & 9.4 & 281.4 & 171.5 & 996.5 \\
AP & 1.7 & 18.4 & 10.0 & 319.1 & 126.9 & 969.1 \\
& & & & & & \\
\hline
\end{tabular}

spans the 968-1984 period. AGRs are similar between sites, ranging from 0.92 (AP) to $1.02 \mathrm{~mm} \mathrm{yr}^{-1}$ (AL) (Table 2, Fig. 3a). Maximum PO estimates are $237 \mathrm{yr}$ for AT, 250 for AL, and 306 for AP, which are adequate when considering an age of $1017 \mathrm{yr}$ on a $\sim 35 \mathrm{~cm}$ radius of the same tree (no. ABS5).

Age class splitting separates the MSL in 529, 299 and $144 \mathrm{yr}$ for the old, middle, and young trees, respectively, with corresponding growth rates ranging from 0.59 (old) to $1.53 \mathrm{~mm} \mathrm{yr}^{-1}$ (young) (Fig. 3c). Fast and slow growth-rate groups are distinctively differentiated by the splitting method, with an AGR

AT

54 series, MSL 275

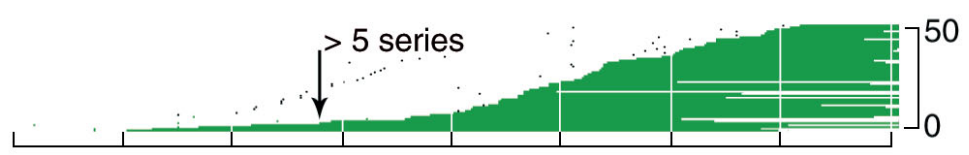

AL

124 series, MSL 397
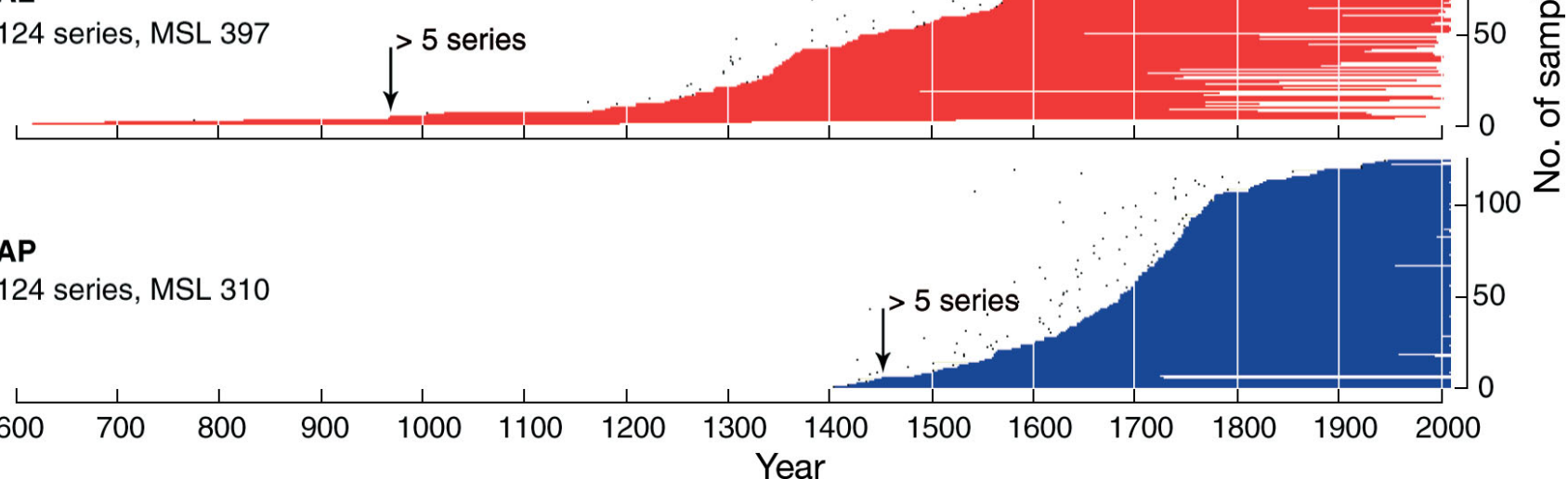

Fig. 2. Replication of 3 Albanian site chronologies (AT: Thethi, AL: Fushe Lura, AP: Cuka Partisan). Bar: 1 individual sample, black dots: estimated germination age. Black arrows: sample size threshold of 5 series. MSL: mean segment length
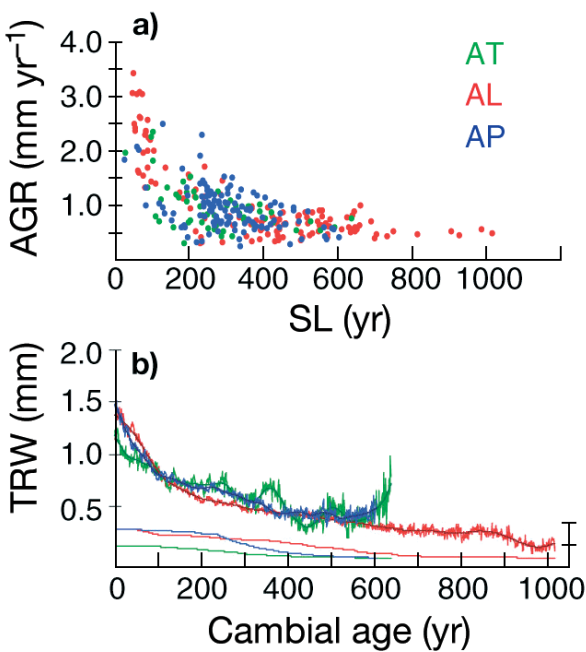

c)
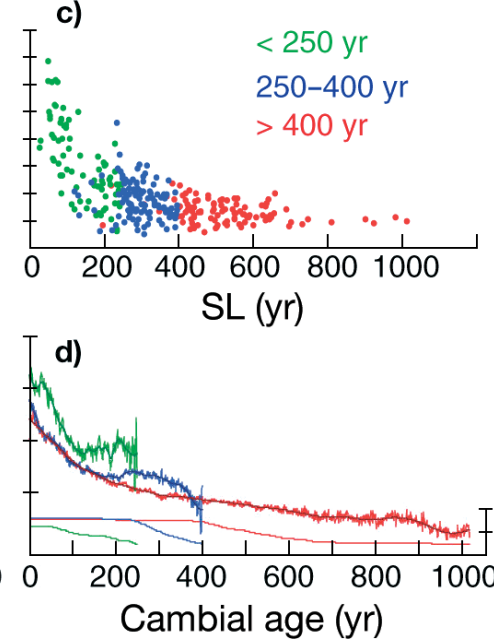
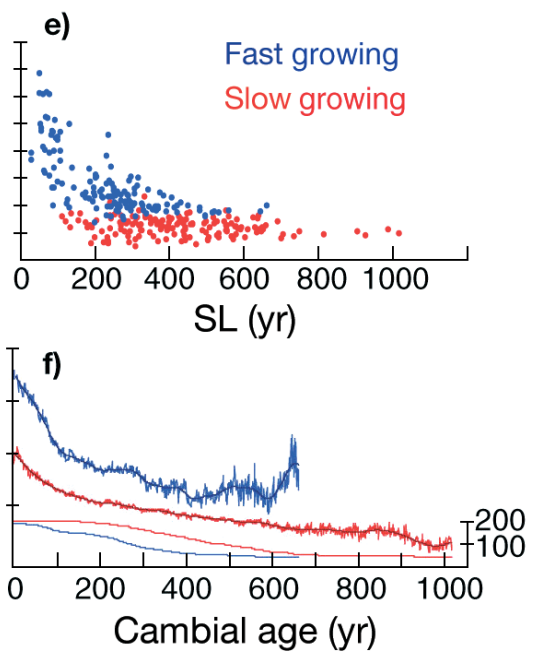

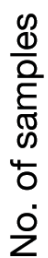

Fig. 3. Average growth rate (AGR) of trees by (a) site (AT, AL, AP; see Fig. 1), (c) age class and (e) slow vs. fast growth rate. Mean growth (TRW: tree ring width) trends (upper lines) and replication (lower lines) after age-alignment by (b) site, (d) age class, and (f) growth rate group. SL: segment length 


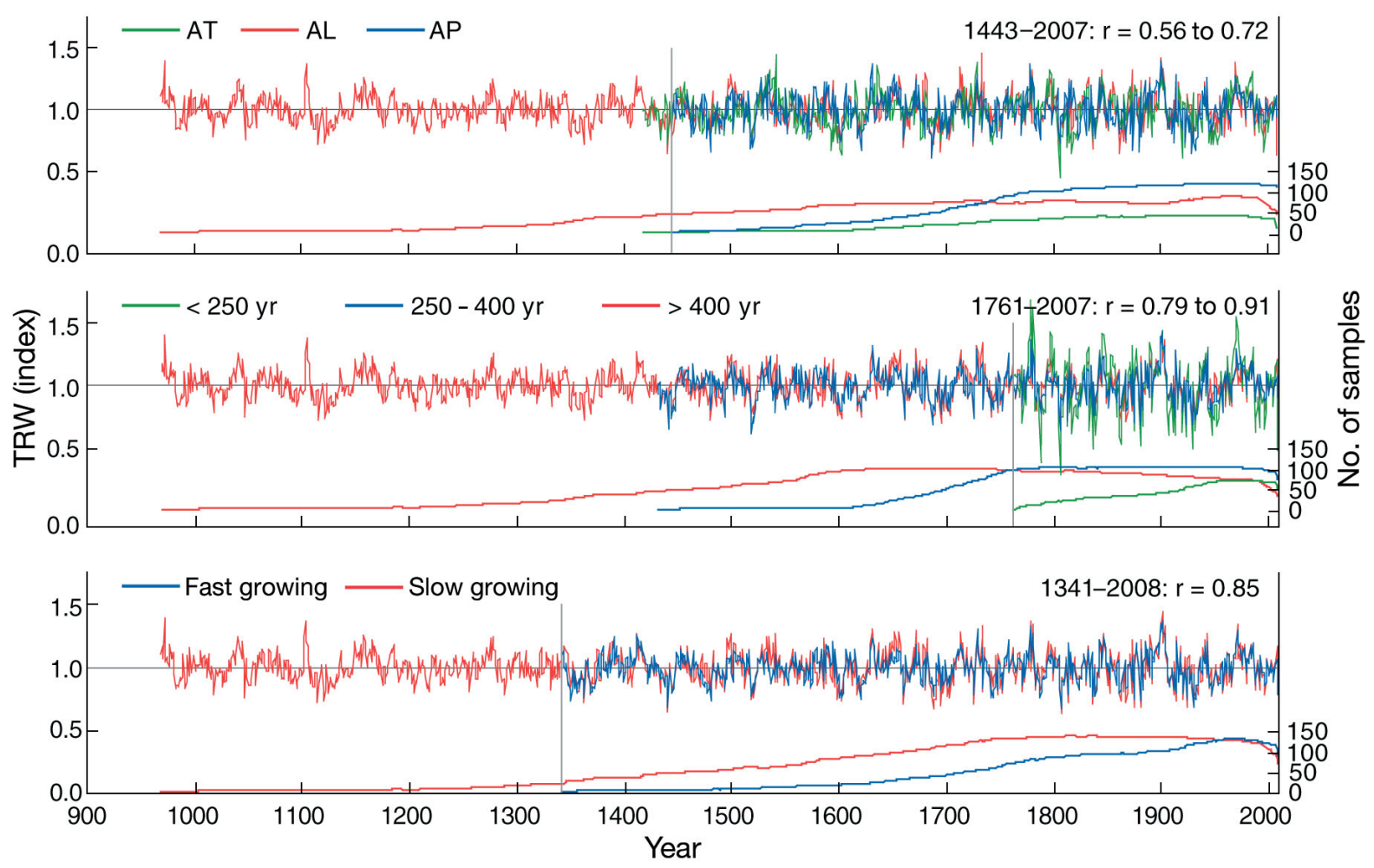

Fig. 4. Power transformed 150 yr spline (PT 150 yr SPL) detrended tree-ring width (TRW) chronologies at 3 sites (AT, AL, AP; see Fig. 1), for 3 age classes, and for slow- vs. fast-growing tree series after truncation at $<5$ series. Pearson's correlation coefficient (r) was calculated for the individual common period (vertical grey line)

of $1.37 \mathrm{~mm} \mathrm{yr}^{-1}$ for the fast-growing trees and $0.59 \mathrm{~mm}$ $\mathrm{yr}^{-1}$ for the slow-growing trees, corresponding to the growth rates of the age class splitting (Fig. 3e).

The growth curves of the 3 sites generally suggest similar levels and trends, but with higher variations at AT, possibly related to the smaller sample size at this site. As expected, splitting the dataset into age classes accentuated the highest growth level for young trees. The growth trends of middle and old age classes were, however, nearly identical as long as replication was similar (Fig. 3b,d,f). Grouping into age classes and growth rates respectively resulted in similar age-related growth trends but different growth levels (Fig. 3d,f).

Growth variations of the PT 150 yr SPL detrended site chronologies show strong conformity on interannual to multi-decadal time-scales (Fig. 4). EPS statistics were robust from 1460 onwards at AT, from 1295 at AL, and from 1510 at AP. Pearson's correlation coefficients between the 3 site chronologies show strongest relations between sites close to each other, with AT-AL correlating at $0.68, \mathrm{AL}-\mathrm{AP}$ at 0.72 , and the most distant AT-AP at 0.56, computed over the common period 1443-2007. Correlations between chronologies of old and middle age classes are nearly identical $(r=0.91)$, and the youngest and oldest trees correlate only slightly less $(r=0.79)$ (both $\mathrm{p}<0.01$ ) for the 1761-2008 period. The same holds for the fast and slow growth-rate groups with $\mathrm{r}=0.85$ (1341-2008, $\mathrm{p}<0.01)$.

The longest records ( $\mathrm{AL}$, old age class, slow-growing trees) cover the time from 968-2008 and include the period of the Medieval Climate Anomaly prior to 1300 with 20 trees. High variations prior to 1150 are likely caused by the low replication ( 7 trees) during this period. TRW values of young trees show higher variations, especially in the 18th and 19th centuries. This effect might be caused by more individual noise during the juvenile period of tree growth (e.g. Carrer \& Urbinati 2004), which is reflected in the lowest Rbar value of 0.45 for trees $<250$ yr (Table 2).

\subsection{Albanian composite chronology}

After truncation at a minimum sample size of 5 series, the ALB chronology spans the period of 968-2008 (Fig. 5). Robust EPS and Rbar statistics are recorded from 1290 onwards, which can be explained by the low replication during the first $300 \mathrm{yr}$ of the record (986-1295) (Fig. 5b). The mean Rbar scatters around 0.52 (Table 2). 
Table 2. Characteristics of site chronologies combined in the Albanian dataset. Elevation, number of trees and series, covered time span (period), average growth rate (AGR), mean segment length (MSL), mean inter-series correlations of raw chronologies (Rbar), expressed population signal (EPS), and 1st yr autocorrelation (L-1) of raw and power transformed (PT) 150 yr spline detrended (150 yr SPL) chronologies. AT: Thethi, AL: Fushe Lura, AP: Cuka Partisan, ALB: Albania

\begin{tabular}{|c|c|c|c|c|c|c|c|c|c|c|c|}
\hline Group & $\begin{array}{c}\text { Elevation } \\
\text { (m a.s.l.) }\end{array}$ & $\begin{array}{c}\text { Trees } \\
\text { (n) }\end{array}$ & $\begin{array}{l}\text { Series } \\
\text { (n) }\end{array}$ & Period & $\begin{array}{c}\text { Period } \\
>5 \text { series }\end{array}$ & $\begin{array}{c}\text { AGR } \\
\left(\mathrm{mm} \mathrm{yr}^{-1}\right)\end{array}$ & $\begin{array}{l}\text { MSL } \\
\text { (yr) }\end{array}$ & Rbar & EPS & $\begin{array}{l}\text { L-1 } \\
\text { Raw }\end{array}$ & 1 PT \\
\hline \multicolumn{12}{|l|}{ Site } \\
\hline AT & 1700-1900 & 41 & 54 & $1303-2007$ & $1417-2007$ & 0.94 & 275 & 0.54 & 0.91 & 0.76 & 0.48 \\
\hline $\mathrm{AL}$ & 1800-2000 & 99 & 124 & $617-2008$ & 968-2008 & 1.02 & 397 & 0.53 & 0.91 & 0.91 & 0.26 \\
\hline $\mathrm{AP}$ & $1900-2100$ & 77 & 124 & $1405-2008$ & 1443-2008 & 0.92 & 310 & 0.57 & 0.95 & 0.66 & 0.34 \\
\hline \multicolumn{12}{|l|}{ Age class } \\
\hline$<250 \mathrm{yr}$ & & 74 & 80 & $1285-2008$ & $1760-2008$ & 1.53 & 144 & 0.45 & 0.90 & 0.80 & 0.46 \\
\hline $250-400 \mathrm{yr}$ & & 83 & 115 & 1334-2008 & 1429-2008 & 0.87 & 299 & 0.52 & 0.85 & 0.85 & 0.29 \\
\hline$>400 \mathrm{yr}$ & & 67 & 107 & $617-2008$ & 968-2008 & 0.65 & 529 & 0.53 & 0.91 & 0.92 & 0.29 \\
\hline \multicolumn{12}{|l|}{ Growth rate } \\
\hline Fast growing & & 105 & 144 & $1237-2008$ & 1340-2008 & 1.37 & 243 & 0.52 & 0.89 & 0.81 & 0.41 \\
\hline Slow growing & & 125 & 158 & $617-2008$ & 968-2008 & 0.59 & 428 & 0.52 & 0.91 & 0.92 & 0.21 \\
\hline \multicolumn{12}{|l|}{ Composite } \\
\hline $\mathrm{ALB}$ & $1700-2100$ & 217 & 302 & $617-2008$ & 968-2008 & 0.96 & 284 & 0.52 & 0.91 & 0.89 & 0.28 \\
\hline
\end{tabular}

Effects of the different detrending methods are emphasized for the ALB composite (Fig. 5). The 9 detrending techniques reveal consistent results in high- to low-frequency domains, but show strong differences between the PT and non-PT records. This is mainly reflected in the standard deviation (Fig. 5): the mean standard deviation calculated for the PT records averages $\sim 0.11$, whereas without PT it is higher at 0.17 . This result confirms the reduction of variance inflation and time series stabilization by PT.

The strong increase of the RCS detrended records at both ends of the time-series, prior to 1300 and in the 20th century, suggests a so-called 'end-effect' phenomenon (Cook \& Peters 1997, Büntgen et al. 2005). In the period from 1300 to 1900, the differences between detrending techniques are minimized and the records strongly agree.

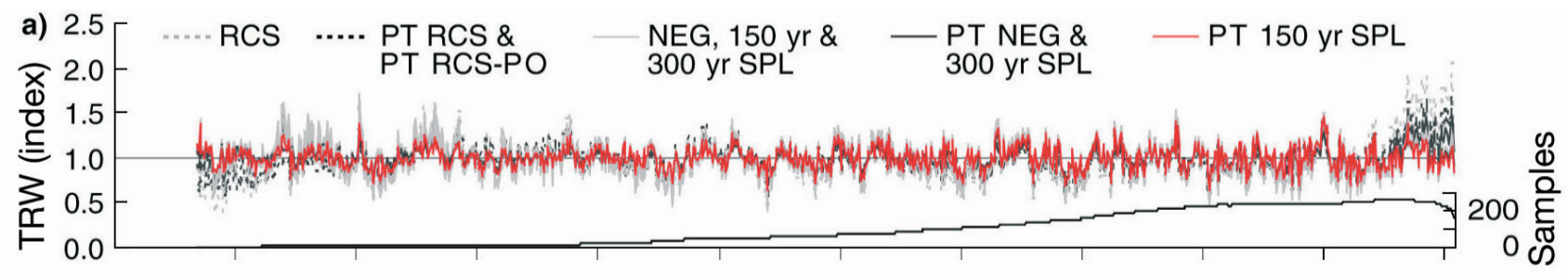

b)
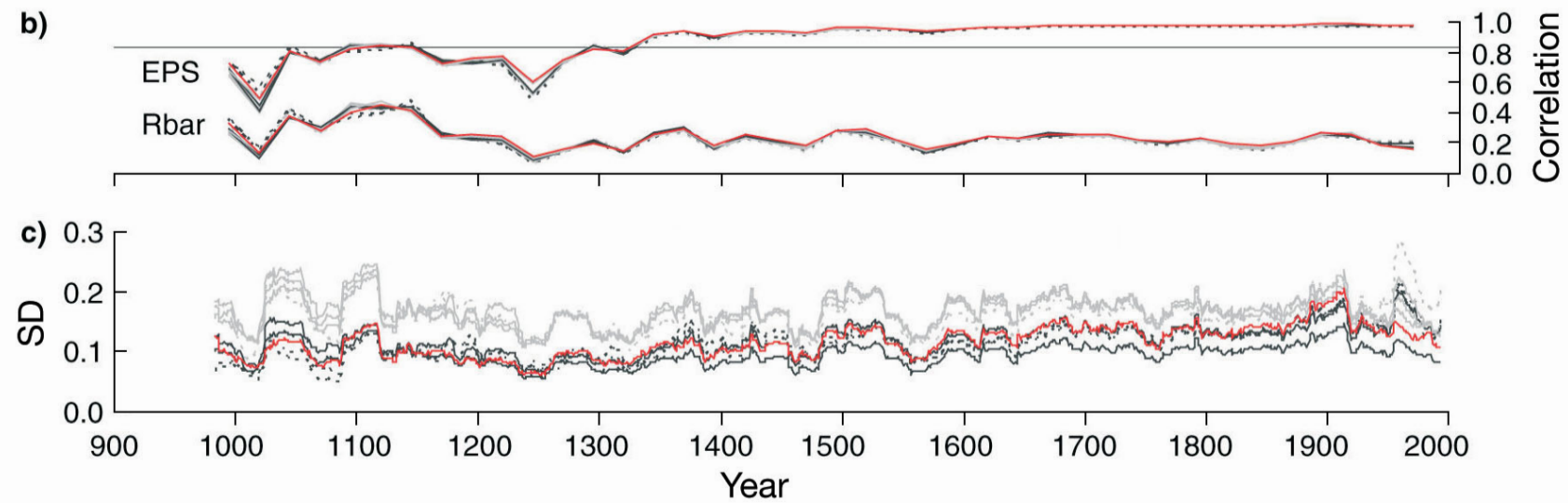

Fig. 5. (a) Comparison of Albanian (ALB) chronology after different detrendings and a minimum sample size of 5 series (lower black line): regional curve standardization (RCS; grey dashed line) and power transformed (PT) RCS with and without pith offset (PO; black dashed lines), negative exponential (NEG), $150 \mathrm{yr}$ and $300 \mathrm{yr}$ spline (SPL) without PT (grey solid lines), PT NEG and PT 300 yr SPL (black solid lines), and PT 150 yr SPL (red solid line) with their respective (b) expressed population signal (EPS; horizontal line indicates 0.85 threshold) and inter-series correlation (Rbar) values, and (c) each moving 31 yr SD. Only the ranges of the different detrendings are shown, which highlight the end-effect issue of the RCS (a) and the dampening effect of the PT (c) 

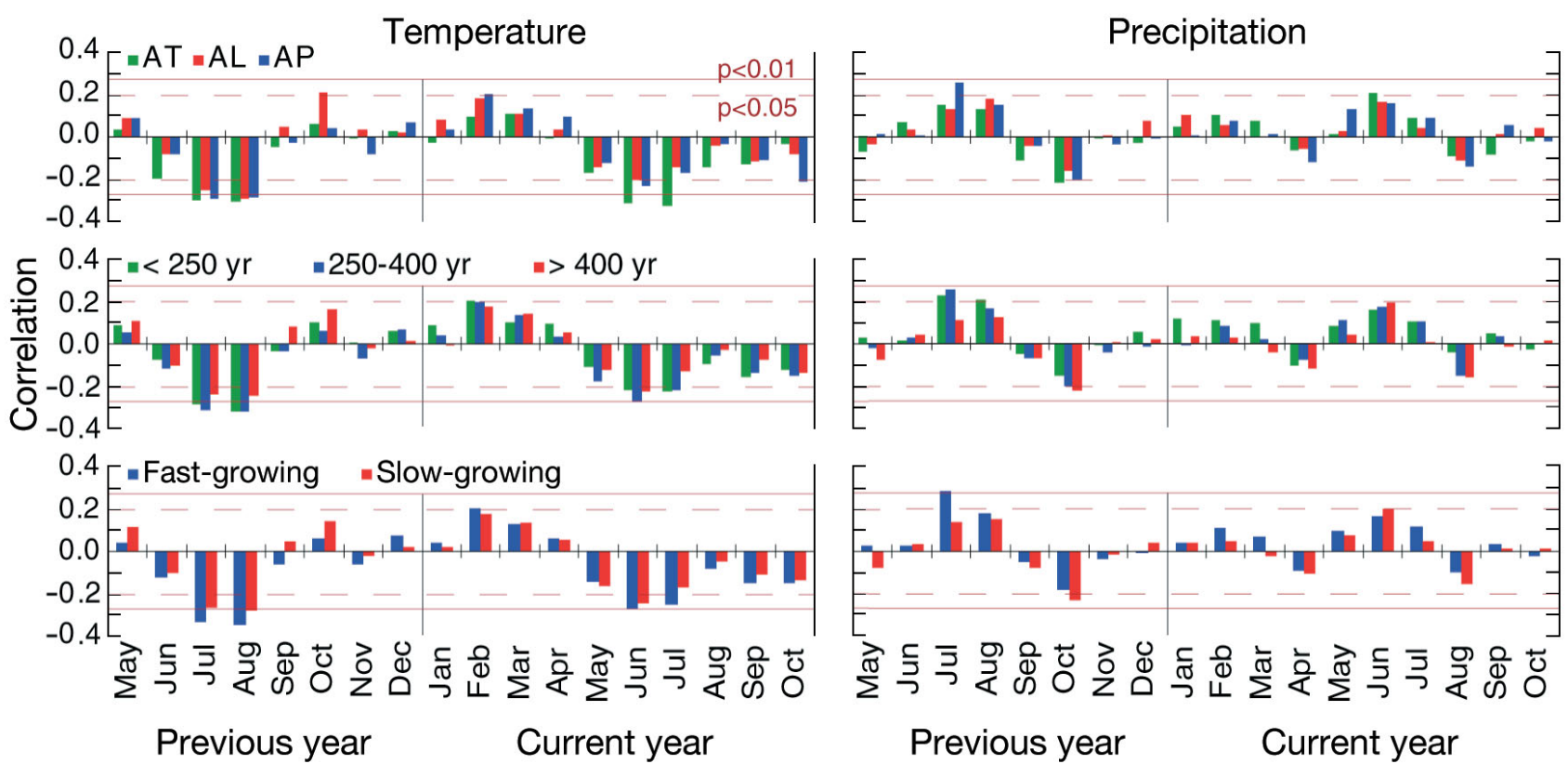

Fig. 6. Sub-chronologies (site subsets, age classes, growth groups) correlated with averaged gridded temperature and precipitation data (CRUTS3) for the 1901-2002 period. Solid (dashed) red lines indicate 99\% (95\%) significance level. AT: Thethi, AL: Fushe Lura, AP: Cuka Partisan

\subsection{Growth-climate relationships}

First we tested the response to temperatures and precipitation from the previous year's May to the current October of TRW formation for the 3 site chronologies, the 3 age classes, and the fast- and slowgrowing tree groups (Fig. 6). Overall, correlations computed over the common 1901-2002 proxy-target period are not high (maximum r-value: -0.33 for AT versus July temperature). From all 144 correlations calculated for temperature and precipitation each, only 11.1 and $0.7 \%$, respectively, reached the $99 \%$ significance level.

Nevertheless, some systematic and robust patterns appeared. In general, tree growth correlated negatively to temperatures of previous July and August as well as current June and July, and positively, albeit not significantly, to winter (February and March) temperatures of the current year (Fig. 6). Correlations with precipitation were positive, but weaker and mostly restricted to previous June and current July. Regarding site-specific patterns, the AT site seemed to be slightly more sensitive to temperature and precipitation variations of the current summer than the other regions. Regarding age and growth groups, the young, middle, and fast-growing trees correlated slightly stronger to the variables and seasons described above than the old and slowgrowing groups.
In a next step, we repeated the climate correlation calculations using the PT ALB composite chronology with the 5 detrending methods applied (Fig. 7), and including scPDSI. Generally, correlation values were in the range of the subset results, with a negative response to temperatures of the previous and current summer and positive response to temperatures of current February. Positive correlations to scPDSI suggest current June and July as the most relevant season for tree growth variability, with $\mathrm{r}=0.22(\mathrm{p}<$ 0.01 ). When applying the RCS-detrended, low-frequency weighted versions of the ALB composite, the winter signal is improved (DJF: $r=0.21, p<0.01$ ) compared to the regional subsets. The PT $150 \mathrm{yr}$ SPL, containing mainly the inter-annual to multi-decadal frequency domains, generally correlates highest in the most relevant summer months.

The overall negative response to summer temperatures and the positive response to summer precipitation suggest that tree growth of Pinus heldreichii is mainly controlled by drought conditions, which is supported by positive correlations to scPDSI during this season, especially in the high-frequency domain (PT 150 yr SPL). Moving correlation patterns shown for tree growth to the highest correlating combination of June and July climate variables suggest an enhanced sensitivity to drought in the middle of the 20th century and decreased strength of the climate signal before and afterwards (Fig. 7b). 
a) Temperature
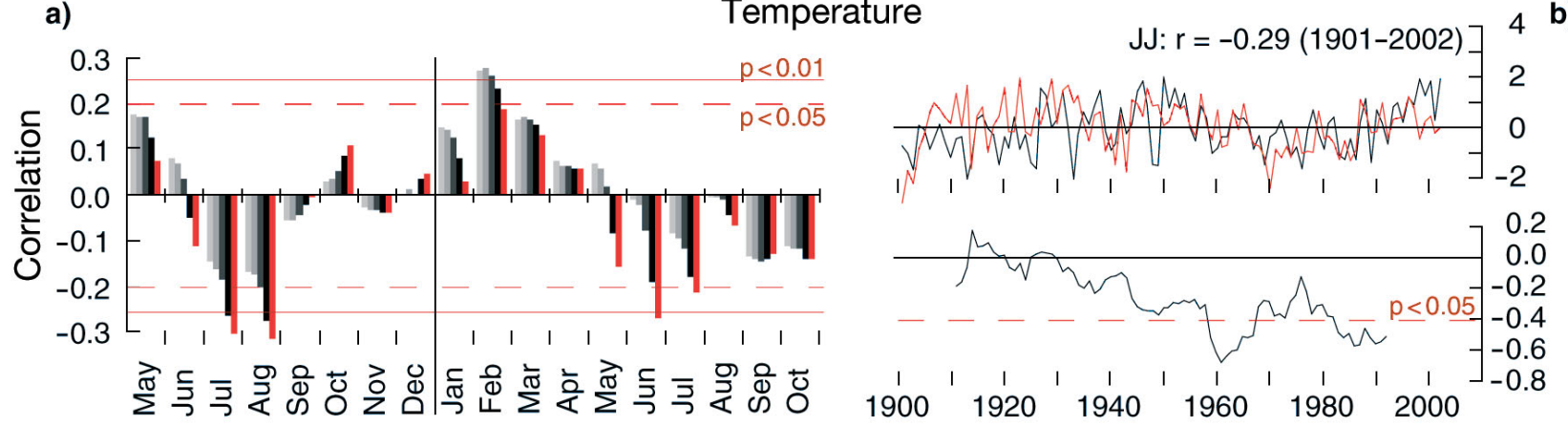

b)

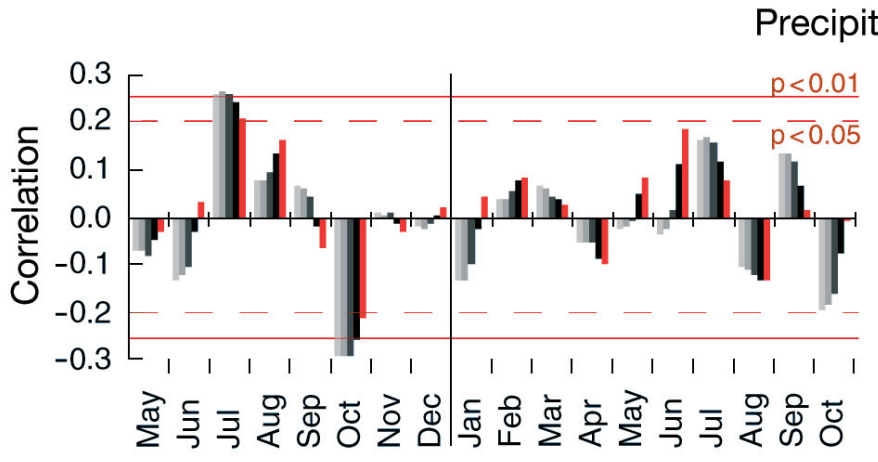

ation

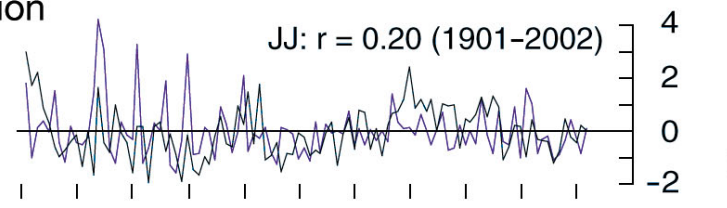

Drought (scPDSI)
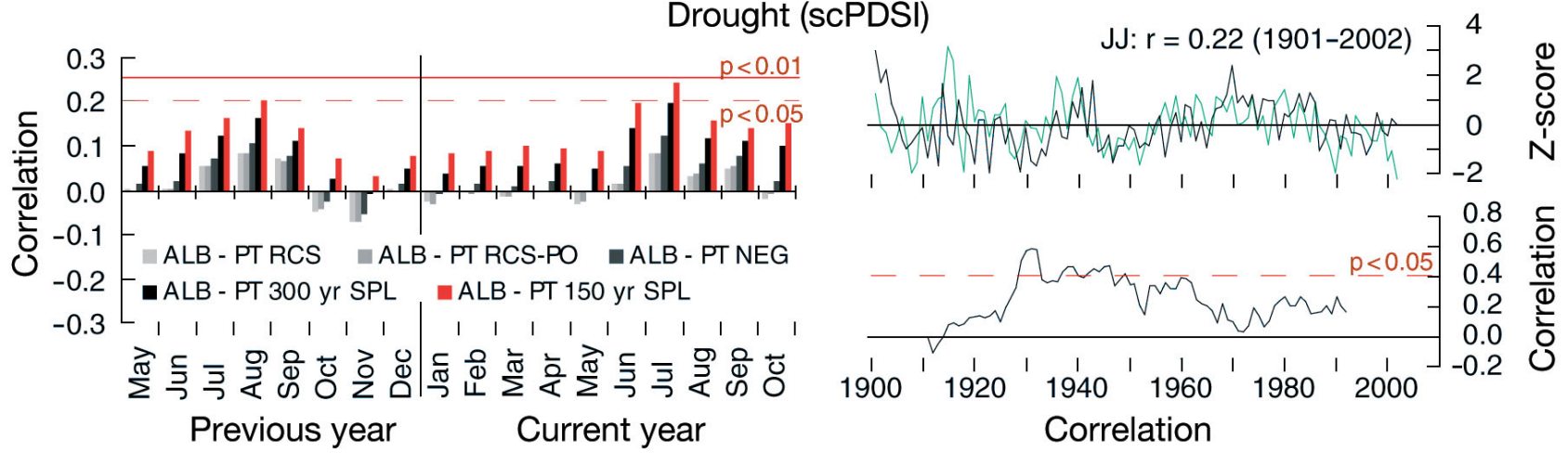

Fig. 7. (a) Growth-climate response of ALB TRW chronologies (power transformed RCS-PO, NEG, 150 yr and 300 yr SPL; see Fig. 5 for abbreviations) to averaged gridded temperature, precipitation, and drought data (CRUTS3) calculated over the 1901-2002 period. (b) Z-scores computed for the PT 150 yr SPL (black) against Jun-Jul (JJ) temperature (inverse; red), precipitation (blue), and scPDSI (green), and their respective $21 \mathrm{yr}$ moving correlation (Pearson's r) underneath. Solid (dashed) red lines: $99 \%(95 \%)$ significance level

\section{DISCUSSION}

\subsection{Chronology characteristics}

We were able to develop a long and well-replicated composite TRW chronology documented for the Balkan Peninsula and the eastern Mediterranean region reaching a maximum of $1392 \mathrm{yr}$ back in time (617 to 2008). This was possible due to favourable conditions such as (1) the presence of long-living trees reaching ages $>1000 \mathrm{yr}$, (2) Pinus heldreichii's high resistance to biological degradation as a result of a high amount of diterpene neutrals in its resin (Lange et al. 1994) resulting in decade-to-century long preservation of dead wood, and (3) environmental conditions protecting against decay such as dry summers, snow cover in winter and rocky shallow soils. In comparison, the longest nearby $P$. heldreichii chronologies span periods of $762 \mathrm{yr}$ (1243 to 2004) in Greece (Kuniholm \& Striker 1987), $758 \mathrm{yr}$ (1250 to 2008) in Bulgaria (Panayotov et al. 2010), and 827 yr (1148 to 1974 ) in South Italy (Serre-Bachet 1985).

The high common variance amongst our 3 sites, particularly in the high- to medium-frequency do- 
main, suggests that tree growth is controlled by similar factors across Albania. Although the replication of the dataset decreases back in time, robust Rbar and EPS statistics are recorded from $~ 1290 \mathrm{AD}$ onwards. Over 600 yr (1300 to 1900), the ALB chronology showed similar growth variability, while strong differences appear at the ends of the differently detrended composite chronologies. High deviations in variance prior to 1300 might be caused by the reduced sample depth and individual tree growth in the juvenile phase of the pines and probably affect the strength of Rbar. Changes in variance in the 20th century are probably also caused by an increasing number of young trees in this period. This bias is enhanced after applying RCS with all modifications in comparison to the other standardization methods and is known as the so-called end-effect issue (Büntgen et al. 2005). It results from the growth curve application that forms the ends of the records in a reciprocal shape (Cook \& Peters 1997). Herein, the adaptive power transformation dampens this bias to a certain point, while individual spline detrending shows no such increase in the most recent decades.

\subsection{Growth-climate relationships}

Despite the strong observed common signal, the response to climate of the 3 site chronologies, the age classes and growth-rate groups, and the differently detrended ALB chronologies, is not particularly strong or robust. Negative correlations to summer temperature combined with positive correlations to summer precipitation suggest an overall tendency to drought sensitivity of the pines. It has to be noted, however, that all correlations over the 1901-2002 period are relatively low and only in a few cases exceed the $99 \%$ significance level. The low correlation values could at least partly be related to the sparse availability of regional meteorological station data for Albanian high-elevation sites and also for the whole Balkan region, resulting in a limited representation of the gridded CRU data for the study region. However, seasonal temperature means and precipitation amounts show a north-south gradient (AT-AP) towards a warmer and drier climate as described by Jaho et al. (1975) and shown in Fig. 1, which seems to correspond to the slighter higher growth-climate response at the most northern AT site.

Nevertheless, our findings using the Albanian TRWchronology correspond well to results of other studies on the same species growing under similar site conditions, i.e. at higher elevation sites and on dry and steep rocky slopes. Panayotov et al. $(2009,2010)$ and Scheithauer et al. (2009) observed a similar growth response at high elevation in the Pirin Mountains in Bulgaria, and Todaro et al. (2007) presented comparable results from a Pinus heldreichii var. leucodermis (Antoine) chronology from Mount Pollino (2054 m a.s.l.) in southern Italy. In all studies, the correlations between TRW and the various instrumental climate data (monthly temperature and precipitation) were relatively weak and not robust over the 20th century proxy-target period. Even for the western Mediterranean basin, Büntgen et al. (2010) reported similar results based on 3 conifer species from the Pyrenees.

The instability in the climate signal might be related to temporally varying climatic influence on tree-growth on inter-annual to decadal timescales as also observed by Andreu et al. (2007). In particular, the decrease in drought sensitivity in the last $40 \mathrm{yr}$ (Fig. 7b) seems to be partially associated with an increase in water-use efficiency due to elevated atmospheric carbon dioxide as hypothesized by Penuelas et al. (2008) and Linares et al. (2009), for instance.

Although sampling in Albania was performed at the highest forested elevations (up to $2100 \mathrm{~m}$ a.s.l.), our 3 sites might not fully represent typical treeline conditions. The thermal tree line of Pinus heldrechii at the Olymp (Greece) ranges from 2200 to $2400 \mathrm{~m}$ a.s.l. with the krummholz zone even reaching elevations of 2500 to $2700 \mathrm{~m}$ a.s.l (Brandes 2007). Körner (1998), on the other hand, states that Mediterranean treeline sites do not show a clear temperature controlled growth pattern compared to the Alpine region and that it is questionable if sampling at the upper zone provides more defined growth control.

The major reason for the absence of a clear climatic signal is assumed to be related to a complex combination of climate factors, i.e. high temperature means and low precipitation amounts, dominating tree growth during summer, as is usually observed for the Mediterranean region (e.g. Gutiérrez 1989, Xoplaki et al. 2003, 2004, Nicault et al. 2008, Büntgen et al. 2010).

The similar climate response patterns of different age classes and growth-performance groups in our study support this hypothesis. Our analyses of various age classes and growth levels indicate that young, middle, and fast-growing trees are more sensitive to drought conditions particularly in the driest months, June and July, than the age class $>400 \mathrm{yr}$ and the slow-growing trees. Studies focusing on agedependent growth-climate relations indicate that cambial activity of young trees starts $\sim 2$ to $3 \mathrm{wk}$ earlier, that environmental information is thus inte- 
grated over a longer time period, and that the response to environmental changes occurs faster (Linderholm \& Linderholm 2004, Rossi et al. 2008, Rozas et al. 2009). The development of root systems may also play a significant role since young trees with shallow roots reach less water from deeper soil layers and, hence, respond more directly to variations in soil water availability (Vaganov et al. 2006).

Moreover, the natural tree line occurs as an open forest steppe in which young trees form more narrowly spaced groups with potentially increased competition for vital environmental resources such as light, water and nutrients. The weaker strength of the climate signal contained in very old tree rings, e.g. 400 to $1000 \mathrm{yr}$, is linked with minimal growth rates and individual growth variation related to tree mortality (Frank et al. 2007). Contrary to our results are findings by Carrer \& Urbinati (2004) and references therein, obtained in the Italian Alps, where climate sensitivity increases with tree age. However, those comparisons are generally limited by local conditions and intensity of past human impacts, which leads to highly varying forest ages and thus, the definition of old trees becomes rather relative.

Growth-climate relations of the differently detrended versions of the ALB chronology highlight the importance of carefully adapting the detrending to the frequency provided by the target. In summer, when drought tends to drive tree growth, the high-frequency weighted $150 \mathrm{yr}$ SPL series appears to best capture the white noise spectrum of the target (Mitchell \& Jones 2005), whereas in winter, when temperature tends to drive tree growth, the RCS detrended series containing more low frequency trends, which best capture the more red-noise-weighted character of temperature. Follow-up studies should be based on tree-ring parameters such as maximum latewood density and stable isotope ratios that are expected to be more climate sensitive in the Mediterranean region (Andreu et al. 2008, Seim et al. 2010, Trouet et al. 2012). Also these studies will have to take the spectral patterns of targets and proxies into account, which enable the development of robust millenniumlong climate reconstructions containing the whole range of low to high frequency signals.

\section{CONCLUSION}

Our new millennium-long TRW chronology from Albania is an important step towards a denser treering network in the Mediterranean and especially in the Balkan region.
The consistently strong common growth variation within and between sites indicates that tree growth at high elevations in Albania is subject to similar ecological conditions. Its summer drought signal, however, remains relatively weak and not stable in the 20th century, making a robust climate reconstruction challenging. Reasons for this low climate signal might be found in (1) the scarcity and brevity of representative climate data available in this region, and (2) the drought signal itself and its temporal instability. Nevertheless, our results provide an important basis for additional tree-ring parameters such as maximum latewood density and stable isotope ratios to be processed, and hence to fully exploit the potential for climatic reconstructions. In addition, our unique dataset serves as a highly valuable reference for dendroarchaeological investigations as well as network analyses towards a better understanding of the complex climate system in the Mediterranean region.

Acknowledgements. We are thankful to K.-F. Rittershofer for logistical coordination of the first (2007) field trip, to J. Vanmoerkerke for support in the field, and to T. Wieloch and K. Häne for lab support. D. Frank, J. Esper and 3 reviewers provided discussion and helpful suggestions. The study was supported by the European Science Foundation (2909 'Medclivar') and the European Union (GOCE 017008-2 'MILLENNIUM').

\section{LITERATURE CITED}

Akkemik Ü, D'Arrigo R, Cherubini P, Köse N, Jacoby GC (2008) Tree-ring reconstructions of precipitation and streamflow for north-western Turkey. Int J Climatol 28: 173-183

Andreu L, Gutiérrez E, Macias M, Ribas M, Bosch O, Camarero JJ (2007) Climate increases regional treegrowth variability in Iberian pine forests. Glob Change Biol 12:804-815

Andreu L, Planells O, Gutiérrez E, Helle G, Schleser G (2008) Climatic significance of tree-ring width and $\delta^{13} \mathrm{C}$ in a Spanish pine forest network. Tellus 60B:771-781

Barbero M, Loisel R, Quézel P, Richardson DM, Romane F (1998) Pines of the Mediterranean Basin. In: Richardson DM (ed) Ecology and biogeography of Pinus. Cambridge University Press, Cambridge, p 153-170

Becker M, Bert GD, Bouchon J, Dupouey JL, Picard JF, Ulrich E (1995) Long-term changes in forest productivity in northeastern France: the dendrochronological approach. In: Landmann G, Bonneau M (eds) Forest decline and atmospheric deposition effects in the French mountains. Springer, Berlin, p 143-156

Bräker OU (1981) Der Alterstrend bei Jahrringdichten und Jahrringbreiten von Nadelhölzern und sein Ausgleich. Mitt Forstl Bundesvers Wien 142:75-102

Brandes R (2007) Waldgrenzen griechischer Hochgebirge: unter besonderer Berücksichtigung des Taygetos, Südpeloponnes. PhD thesis, University of Erlangen 
Büntgen U, Esper J, Frank DC, Treydte K, Schmidhalter M, Nicolussi K, Seifert M (2005) The effect of power transformation on RCS: evidence from three millennial-length alpine chronologies. In: Gärtner H, Esper J, Schleser G (eds) TRACE: Tree rings in archaeology, climatology and ecology. Forschungszentrum Jülich, Jülich, p 141-149

Büntgen U, Frank DC, Grudd H, Esper J (2008) Long-term summer temperature variations in the Pyrenees. Clim Dyn 31:615-631

Büntgen U, Frank D, Trouet V, Esper J (2010) Diverse climate sensitivity of Mediterranean tree-ring width and density. Trees (Berl) 24:261-273

Büntgen U, Tegel W, Nicolussi K, McCormick M and others (2011) 2500 years of European climate variability and human susceptibility. Science 331:578-582

Carrer M, Urbinati C (2004) Age-dependent tree-ring growth responses to climate in Larix decidua and Pinus cembra. Ecology 85:730-740

Cook ER, Peters K (1997) Calculating unbiased tree-ring indices for the study of climatic and environmental change. Holocene 7:361-370

D'Arrigo RD, Cullen HM (2001) A 350-year (AD 1628-1980) reconstruction of Turkish precipitation. Dendrochronologia 19:167-177

Dünkeloh A, Jacobeit J (2003) Circulation dynamics of Mediterranean precipitation variability 1948-98. Int J Climatol 23:1843-1866

> Esper J, Frank D, Büntgen U, Verstege A, Luterbacher J, Xoplaki E (2007) Long-term drought severity variations in Morocco. Geophys Res Lett 34:L17702, doi:10.1029/ 2007GL030844

Frank D, Büntgen U, Böhm R, Maugeri M, Esper J (2007) Warmer early instrumental measurements versus colder reconstructed temperatures: shooting at a moving target. Quat Sci Rev 26:3298-3310

Gao X, Giorgi F (2008) Increased aridity in the Mediterranean region under greenhouse gas forcing estimated from high resolution simulations with a regional climate model. Global Planet Change 62:195-209

Griggs C, DeGaetano A, Kuniholm P, Newton M (2007) A regional high-frequency reconstruction of May-June precipitation in the north Aegean from oak tree rings, AD 1089-1989. Int J Climatol 27:1075-1089

Guiot J, Mathieu L, Munaut AV (1979) Tree-rings and climate in Morocco. Tree-Ring Bull 39:61-75

Gutiérrez E (1989) Dendroclimatological study of Pinus sylvestris L. in southern Catalonia (Spain). Tree-Ring Bull 49:1-9

Holmes RL (1983) Computer-assisted quality control in treering dating and measurement. Tree-Ring Bull 43:69-78

IPCC (2007) Summary for Policymakers. In: Solomon S, Qin D, Manning M, Chen Z and others (eds) Climate change 2007: the physical science basis. Contribution of Working Group I to the Fourth Assessment Report of the IPCC. Cambridge University Press, Cambridge

Jaho S, Mukeli R, Naçi R, Mici A, Boriçi M, Bekteshi P (1975) Klima e Shqipërise (Climate of Albania). Hydrometeorological Institute, Tirana

Körner C (1998) A re-assessment of high elevation treeline positions and their explanation. Oecologia 115:445-459

- Kuniholm PI, Striker CL (1987) Dendrochronological investigations in the Aegean and neighboring regions, 19831986. J Field Archaeol 14:385-398

> Lange W, Stevanovic-Janezic T, Spanoudaki M (1994) Cembratrienols and other components of white bark pine (Pinus heldreichii) oleoresin. Phytochemistry 36: 1277-1279

Levanič T, Toromani E (2010) Austrian pine (Pinus nigra Arnold) tree-ring width chronology from northeast Albania: preliminary results. In: Levanič T, Gričar J, Hafner P, Krajnc R, Jagodic Š, Gaertner H, Heinrich I, Helle G (eds) TRACE: Tree rings in archaeology, climatology and ecology. Forschungszentrum Jülich, Jülich, p 104-109

- Linares JC, Delgado-Huertas A, Camarero JJ, Merino J, Carreira JA (2009) Competition and drought limit the response of water-use efficiency to rising atmospheric carbon dioxide in the Mediterranean fir Abies pinsapo. Oecologia 161:611-624

Linderholm HW, Linderholm K (2004) Age-dependent climate sensitivity of Pinus sylvestris L. in the central Scandinavian mountains. Boreal Env Res 9:307-317

Luterbacher J, Xoplaki E, Casty C, Wanner H and others (2006) Mediterranean climate variability over the last centuries: a review. In: Lionello P, Malanotte-Rizzoli P, Boscolo R (eds) The Mediterranean climate: an overview of the main characteristics and issues. Elsevier, Amsterdam, p 27-148

Macias M, Andreu L, Bosch O, Camarero JJ, Gutiérrez E (2006) Increasing aridity is enhancing silver fir (Abies alba Mill.) water stress in its south-western distribution limit. Clim Change 79:289-313

Mitchell TD, Jones PD (2005) An improved method of constructing a database of monthly climate observations and associated high-resolution grids. Int J Climatol 25: $693-712$

Nicault A, Alleaume S, Brewer S, Carrer M, Nola P, Guiot J (2008) Mediterranean drought fluctuations during the last 500 years based on tree-ring data. Clim Dyn 31: $227-245$

Panayotov M, Bebi P, Krumm F, Yurukov S (2009) Pinus peuce and Pinus heldreichii tree rings as a key to past mountain climate in Southeastern Europe. In: Kaczka RJ, Malik I, Owczarek P, Gärtner H, Heinrich I, Helle G, Schleser G (eds) Tree rings in archaeology, climatology and ecology, TRACE 7:71-77

Panayotov M, Bebi P, Trouet V, Yurukov S (2010) Climate signals in Pinus peuce and Pinus heldreichii tree-ring chronologies from the Pirin Mountains in Bulgaria. Trees (Berl) 24:479-490

Penuelas J, Hunt JM, Ogaya R, Jump AS (2008) Twentieth century changes of tree-ring $\mathrm{C}^{13}$ at the southern rangeedge of Fagus sylvatica: increasing water-use efficiency does not avoid the growth decline induced by warming at low altitudes. Glob Change Biol 14:1076-1088

Popa I, Kern Z (2009) Long-term temperature reconstruction inferred from tree-ring records from the Eastern Carpathians. Clim Dyn 32:1107-1117

Rossi S, Deslauriers A, Anfodillo T, Carrer M (2008) Age-dependent xylogenesis in timberline conifers. New Phytol 177:199-208

Rozas V, DeSoto L, Olano JM (2009) Sex-specific, agedependent sensitivity of tree-ring growth to climate in the dioecious tree Juniperus thurifera. New Phytol 182: $687-697$

Scheithauer J, Grunewald K, Helle G, Günther B, Gikov A (2009) Bosnian pine (Pinus heldreichii) as geoarchive at the timberline in the Pirin mountains and on the Balkan Peninsula. Biotechnol Biotechnol Equip 23:96-99

Seim A, Treydte K, Buntgen U, Esper J and others (2010) 
Exploring the potential of Pinus heldreichii Christ for long-term climate reconstruction in Albania. In: Levanič T, Gričar J, Hafner P, Krajnc R, Jagodic Š, Gärtner H, Heinrich I, Helle G (eds) TRACE: Tree rings in archaeology, climatology and ecology. Forschungszentrum Jülich, Jülich, p 75-82

Serre-Bachet F (1985) Une chronologie pluriséculaire du Sud de l'Italie. Dendrochronologia 3:45-66

Todaro L, Andreu L, D'Alessandro CM, Gutiérrez E, Cherubini P, Saracino A (2007) Response of Pinus leucodermis to climate and anthropogenic activity in the National Park of Pollino (Basilicata, Southern Italy). Biol Conserv 137:507-519

Touchan R, Xoplaki E, Funkhouser G, Luterbacher J and others (2005) Reconstructions of spring/summer precipitation for the eastern Mediterranean from tree-ring widths and its connection to large-scale atmospheric circulation. Clim Dyn 25:75-98

Trouet V, Panayotov M, Ivanova A, Frank D (2012) A panEuropean summer teleconnection mode recorded by a new temperature reconstruction from the eastern Mediterranean (1768-2008). Holocene doi: 10.1177/ 0959683611434225

Vaganov EA, Hughes MK, Shashkin AV (2006) Growth

Editorial responsibility: Nils Chr. Stenseth, Oslo, Norway dynamics of conifer tree rings. Springer, New York, NY Vakarelov I, Mirtchev S, Kachaunova E, Simeonova N (2001) Reconstruction of summer air temperatures by dendrochronological analysis of Macedonian pine (Pinus peuce Griseb.) in Pirin mountains (South-eastern Bulgaria). For Ideas 1-4:16-26

van der Schrier G, Briffa KR, Jones PD, Osborn TJ (2006) Summer moisture variability across Europe. Int J Climatol 19:2818-2834

Westphal T, Tegel W, Heussner KU, Lera P, Rittershofer KF (2010) Erste dendrochronologische Datierungen historischer Hölzer in Albanien. Archaeol Anz 2:75-95

Wigley TML, Briffa KR, Jones PD (1984) On the average of correlated time series, with applications in dendroclimatology and hydrometeorology. J Clim Appl Meteorol 23: 201-213

Xoplaki E, González-Rouco JF, Luterbacher J, Wanner H (2003) Mediterranean summer air temperature variability and its connection to the large-scale atmospheric circulation and SSTs. Clim Dyn 20:723-739

Xoplaki E, González-Rouco JF, Luterbacher J, Wanner H (2004) Wet season Mediterranean precipitation variability: influence of large-scale dynamics and trends. Clim Dyn 23:63-78

Submitted: July 8, 2011; Accepted: December 11, 2011 Proofs received from author(s): March 25, 2012 